\title{
EFICACIA DE LA CIRUGÍA MUCOGINGIVAL POSTERIOR A LA ELIMINACIÓN DE UN GRANULOMA PIÓGENO: REPORTE DE UN CASO
}

\author{
Efficacy of mucogingival surgery after removal of a pyogenic \\ granuloma: a case report.
}

\author{
Calderón-Barzallo Mario ${ }^{1^{*}}$, Pereira-Heredia Gabriela ${ }^{2}$, Pulla-Bravo María Eulalia ${ }^{3}$. \\ ${ }^{1}$ Docente de la Universidad Católica de Cuenca, Especialista en Periodoncia. Cuenca, Ecuador \\ 2 Odontóloga general de práctica privada. Cuenca, Ecuador. \\ 3 Odontóloga general de práctica privada. Cuenca, Ecuador. \\ *drmariocalderon@gmail.com
}

\begin{abstract}
Resumen
El objetivo de este artículo es mostrar la efectividad de la cirugía mucogingival en función al colgajo de posición coronal en la cobertura radicular, como tratamiento adjunto en la remoción quirúrgica de un granuloma piógeno que es próximo a la encía marginal de los órganos dentarios antero superior. El granuloma piógeno es una lesión hiperplásica e inflamatoria que se presenta en cualquier zona de la mucosa oral y se origina del tejido conjuntivo del periostio o de la membrana periodontal. Para restituir el defecto residual formado por la remoción de dicho granuloma, se realizó un colgajo de posición coronal en combinación con un injerto de tejido conectivo subepitelial obtenido de la tuberosidad del maxilar, con la finalidad de generar aumento de la encía queratinizada, similitud en el color y recuperación de textura del área tratada. Dando como resultado volumen del tejido gingival y una adecuada estética a nivel de la encía.
\end{abstract}

Palabras clave: Granuloma, colgajo, tejido conectivo, encía, estética. (DeCS).

\begin{abstract}
The objective of this article is to show the effectiveness of mucogingival surgery as a function of the coronal position flap in the root coverage, as an adjunct treatment in the surgical removal of a pyogenic granuloma that is close to the marginal gingiva of the anterior superior dental organs. Pyogenic granuloma is a hyperplastic and inflammatory lesion that occurs in any area of the oral mucosa and originates from the connective tissue of the periosteum or the periodontal membrane. To restore the residual defect formed by the removal of said granuloma, a coronally positioned flap was made in combination with a graft of subepithelial connective tissue obtained from the tuberosity of the maxilla, in order to generate an increase in the keratinized gingiva, provide similarity in the color and texture recovery of the treated area. This results in volume in the gingival tissue and adequate aesthetics at the gum level.
\end{abstract}

Key words: Granuloma, flap, connective tissue, gingiva, esthetic.

\section{Introducción}

El término granuloma piógeno fue introducido por primera vez por Hartzell ${ }^{1}$ en el año 1904. Es una lesión hiperplásica e inflamatoria (neoplasia benigna), que se presenta en cualquier zona de la mucosa oral, pero se encuentra con mayor frecuencia en la encía marginal, se origina del tejido conjuntivo del periostio o de la membrana periodontal. ${ }^{2}$ Se ha encontrado reportes de que el granuloma puede aparecer en los labios, lengua, paladar y dedos; los que afectan a la mucosa labial son raros. ${ }^{3}$

Clínicamente aparece como una masa blanda, de crecimiento rápido, color rojizo y tamaño variable, con una alta tendencia a sangrar. Se puede localizar en la cara vestibular de los dientes anteriores del maxilar superior o en espacios interdentales. Generalmente se desarrolla por trauma, prótesis mal adaptada, caries dental, acúmulo de placa bacteriana o cambios hormonales. ${ }^{4}$ Según la clasificación de enfermedades periodontales y 
periimplantarias del año 2017 incluye al granuloma piógeno como una enfermedad gingival no inducida por placa como proceso reactivo. ${ }^{5}$

Histológicamente se puede observar una formación limitada, al momento del corte presenta una estructura vascular sin compromiso de la mucosa afectada. En el microscopio se puede visualizar que es un tejido granulomatoso que posee abundantes capilares y endotelio fibroso cubierto por células endoteliales gruesas. ${ }^{4}$

Los signos o síntomas no tienen vínculo con el sitio anatómico afectado ni predisposición con el sexo y la edad, aunque varios estudios mencionan mayor frecuencia en el sexo femenino ${ }^{1,5}$ y el $37 \%$ de las lesiones gingivales reactivas en pacientes alrededor de 30 años. ${ }^{6}$

El tratamiento consiste en la exéresis total de la lesión con curetaje subperióstico para evitar recidivas. Cuando se encuentran en una relación cercana al margen gingival puede resultar en la exposición radicular, generando disconformidad al paciente en aspectos estéticos por los cambios de color generados al exponer el cemento radicular al medio bucal e incrementando la sensibilidad dentaria ante estímulos térmicos. ${ }^{6}$

El propósito de este artículo es indicar que, posterior a la eliminación de un granuloma piógeno se puede aplicar el colgajo de desplazamiento coronal para recesiones únicas diseñada por el Dr. Zucchelli ${ }^{7}$ en combinación con un injerto de tejido conectivo sub epitelial para la reconstrucción del tejido mucogingival, el cual ha demostrado resultados óptimos de cobertura radicular, con una adecuada similitud de color y de textura del área tratada con respecto al tejido blando. ${ }^{7}$ Además es un proceso diseñado para maximizar el suministro sanguíneo al injerto, dando como resultado mayor estética, cicatrización rápida y con molestias mínimas. ${ }^{8}$

\section{Reporte de caso}

Paciente de sexo femenino de 25 años de edad acude a la consulta por presentar un abultamiento en la encía que afecta su estética bucodental. Al realizar la anamnesis, la paciente menciona que con el tiempo observó incremento de volumen sin presentar dolor ni antecedentes patológicos.

En la valoración clínica se observa una hipertrofia gingival a nivel de la encía adherida con extensión a la encía marginal libre de forma redonda con superficie aframbuesada, base sésil y de $7 \mathrm{~mm}$ de diámetro entre las piezas dentales 1.2 y 1.3. (Figura $1-\mathrm{A}$ )

Se realizó la historia clínica de la paciente, la toma de fotografías iniciales, terapia periodontal básica y uso de enjuague con clorhexidina al $0.12 \%$. Además, se prescribe orden de laboratorio como examen complementario en el cual se incluyen los valores de IRN para valoración prequirúrgica.
En los datos periodontales encontramos ausencia de sangrado al sondaje, sin formación de bolsa periodontal ni pérdida de inserción clínica, con presencia de un agrandamiento gingival en la encía insertada en relación clínica con granuloma piógeno con involucramiento del margen gingival del órgano dental 1.3.

\section{Procedimiento quirúrgico}

Se procede a la valoración de los exámenes de laboratorio, al no presentar ninguna alteración que imposibilite el acto quirúrgico, el paciente procede a firmar el consentimiento informado. Se aplica anestesia infiltrativa en la zona vestibular y palatina de la zona a ser tratada correspondiente a las piezas dentales 1.2-1.3 y en la zona de la tuberosidad del maxilar como sitio donante del injerto de tejido conectivo subepitelial.

\section{Lecho receptor}

Una vez verificado el efecto anestésico, se procede a realizar una incisión biselada mediante la utilización de una hoja de bisturí $15 \mathrm{c}$ en la periferia de la lesión del tejido blando al ser excisionado, el objetivo del bisel es mantener la mayor parte del tejido epitelial y a su vez contribuye a la eliminación del tejido conectivo que puede estar afectado a nivel de la base de la lesión. Se realiza la remoción de la lesión mediante de una cureta de molt, el elemento excisionado es colocado en formalina al $10 \%$ para su respectivo estudio anatomopatológico. (Figura 1-B)

Posterior a la eliminación del granuloma piógeno se puede observar un defecto mucogingival, que requiere ser tratado para no alterar la estética del paciente. Podría generarse una recesión tipo I de Cairo, ${ }^{9}$ presentaría posible sensibilidad y susceptibilidad a caries. (Figura 1-C)

Con la finalidad de eliminar el defecto creado por la exéresis de dicho granuloma se planifica realizar un colgajo desplazado coronal, basado en la técnica de Zucchelli. ${ }^{10} \mathrm{El}$ modelo del colgajo consistió en las siguientes incisiones: dos incisiones biseladas oblicuas, ligeramente divergentes de 5 $\mathrm{mm}$ de longitud alcanzando la línea mucogingival, inician en la base de la papila interdental distal y mesial a ser tratada, se juntan con una incisión intrasulcular vestibular la cual se une con las incisiones verticales. ${ }^{7}$ (Figura 2)

Posteriormente con la ayuda de tijeras de micro cirugía se procedió a desepitelializar la zona de las papilas interdentales, obteniendo una exposición de injerto del tejido conectivo que va a estar en contacto con la superficie del tejido conectivo de las papilas quirúrgicas creadas en el colgajo. ${ }^{7}$

Para permitir el descenso coronal se eliminaron todas las inserciones musculares del colgajo, la movilización del mismo se consideró óptima cuando la porción marginal alcanza el nivel amelocementario y la liberación del colgajo terminó cuando fue posible reposicionarlo incluso sin suturas. ${ }^{7}$ 

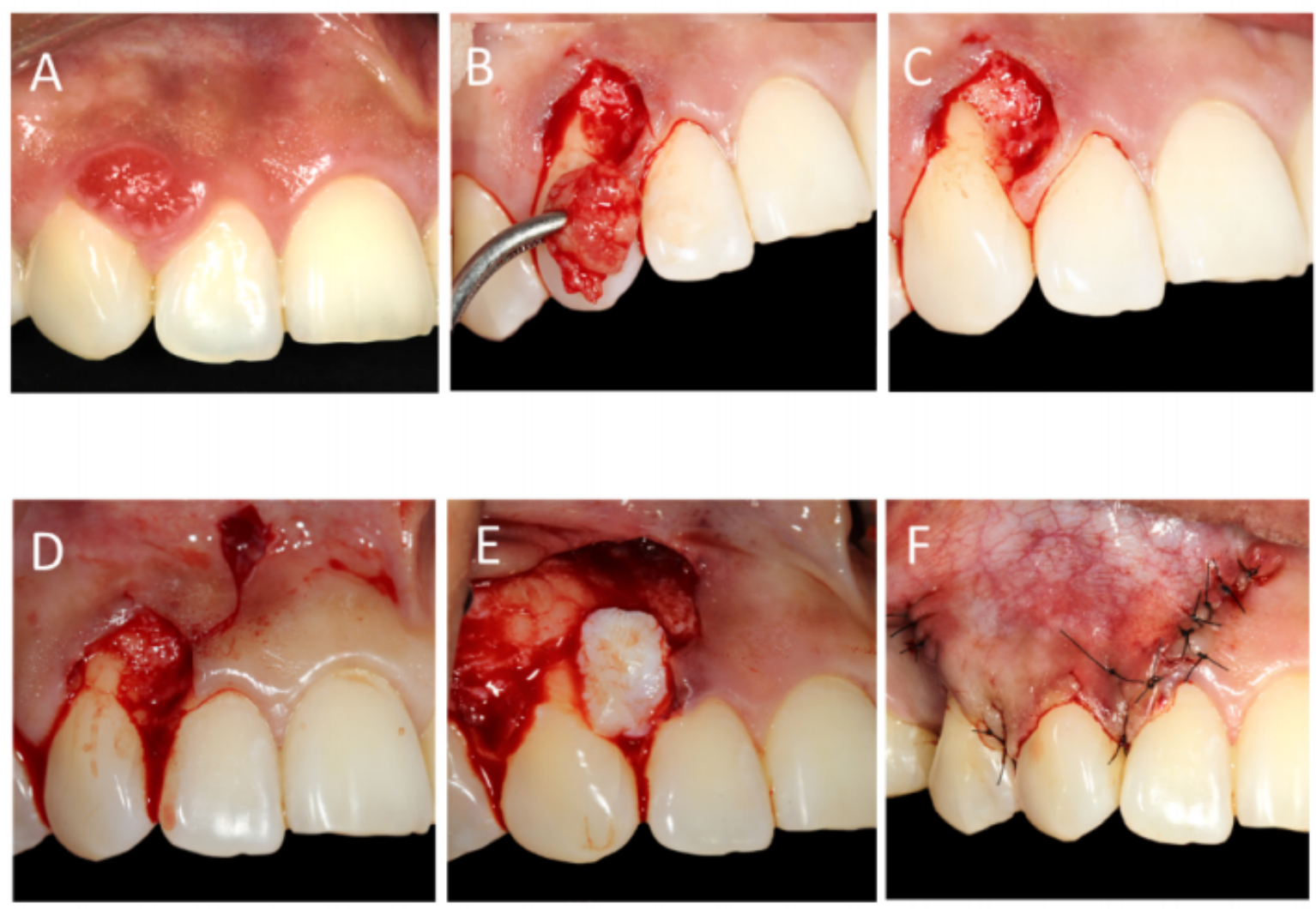

Fig. 1. (A) Vista frontal de la lesión. (B) Excisión quirúrgica. (C) Lesión removida. (D) Desbridamiento del hueso alveolar. (E) Posicionamiento de injerto tejido conectivo (tuberosidad del maxilar) en área receptora. (F) Sutura del colgajo desplazado coronal. (puntos simples - puntos colchonero).

Previo al procedimiento la superficie de la raíz no se trató mecánicamente debido a que no era un cemento radicular contaminado ni expuesto al medio bucal, conservando las fibras del tejido conectivo residuales que aún se mantenían insertadas en el cemento radicular. Procedemos a condicionar el sitio receptor óseo, para realizar un correcto desbridamiento del hueso alveolar con la finalidad de eliminar cualquier vestigio de la lesión excisionada en el sector y permitir un sitio limpio para recibir el injerto de tejido conectivo subepitelial. Cuya función es ayudar a recuperar el tejido gingival eliminado y reconstruir el volumen perdido (fenotipo gingival). ${ }^{7}$ (Figura 1-D)

\section{Área donante}

En relación al tamaño del defecto residual, se decide obtener la cantidad necesaria de tejido conectivo de la zona de la tuberosidad del maxilar,la cual presenta un volumen adecuado que permitirá recuperar el perfil del tejido blando periodontal perdido. Los beneficios del injerto de tejido conectivo subepitelial autógeno se aplican cada vez más en indicaciones estéticas como engrosamiento de tejidos blandos, tratamiento de recesión, preservación de crestas, aumento de crestas de tejidos blandos y reconstrucción de papilas. $^{11}$ La cantidad de tejido necesario para la reconstrucción es potencialmente mayor que la cantidad del defecto. El procedimiento comienza con dos incisiones perpendiculares al tejido en la superficie distal del último molar, con una hoja de bisturí número $15 \mathrm{c}$, a una profundidad de 1.0 a $1.5 \mathrm{~mm}$ y las incisiones deben incluir todo el tejido blando de la superficie distal del diente. ${ }^{11} \mathrm{El}$ injerto se retira del sitio donante mediante una disección aguda, después de su extracción se coloca sobre una gasa estéril humedecida en solución salina hasta su posterior utilización. El área donante se cierra por una sutura colchonero horizontal o se puede utilizar puntos simples para cerrar completamente la herida (Zuhr y Hurzeler 2012). ${ }^{11}$ En el postoperatorio se recomienda presionar la herida para la adaptación del colgajo y su cicatrización. (Figura 1-E)

\section{Posicionamiento del injerto y sutura del colgajo} desplazado coronal

Una vez posicionado el injerto de tejido conectivo en 


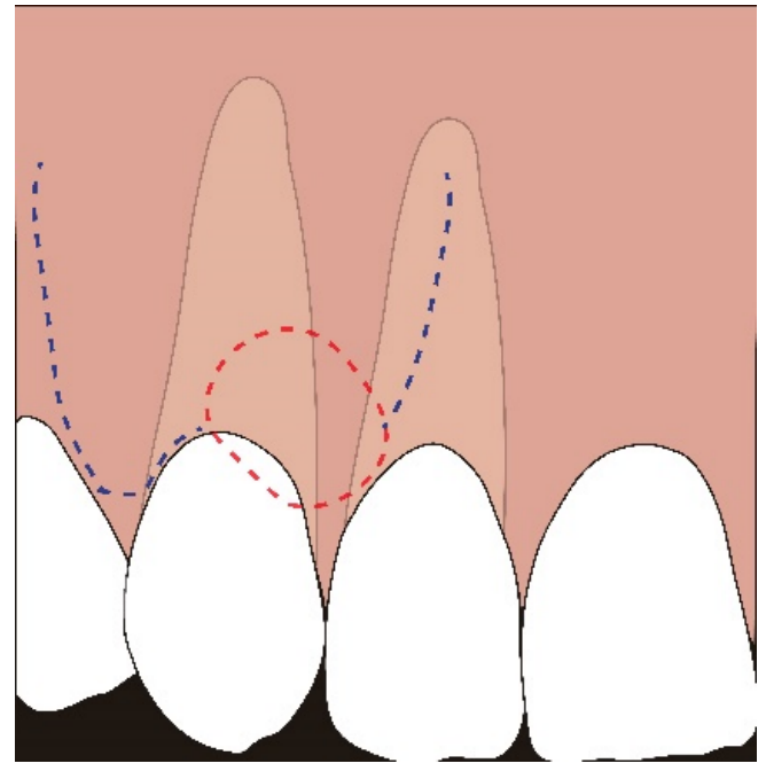

Fig. 2. Incisión para colgajo desplazado coronal, basado en la técnica de Zucchelli. Fuente: Elaboración propia.

el sitio receptor se procede a valorar su estabilidad en el sitio y se realiza el recubrimiento del mismo. El colgajo es estabilizado en una posición más coronal en relación al límite amelocementario, mediante el uso de puntos simples de "Schanelec" en la zona de las incisiones verticales y en la zona de las papilas el colgajo es estabilizado mediante el uso de puntos suspensorios en combinación con puntos simples (nylon 5-0 o 6-0 de la marca Ethilon). ${ }^{12}$ (Figura 3) $\mathrm{Al}$ término de la sutura se observa la estabilidad del colgajo en la nueva posición, esto se realiza mediante tracción del labio, una vez estable en colgajo se procede a realizar la sutura de la zona donante mediante el uso de puntos simples.

\section{Cuidados postoperatorios}

Entre las indicaciones post operatorias se sugiere a la paciente que suspenda el cepillado por 2 semanas en el sitio intervenido, se prescribió clorhexidina $0.12 \%$ cada 12 horas y se indicó medicamento para el control del dolor.

Se realizó controles a los 4 días para la valoración clínica, donde se determina presencia de hematomas o equimosis, a los 8 días limpiezas tópicas con clorhexidina al $0.12 \%$ y control de placa dentobacteriana, a los 15 días se retiró los puntos de sutura y se recibió la confirmación del diagnóstico histológico como granuloma piógeno, a los 21 días se hizo un control con la toma de las fotos intraorales finales. (Figura 4) Se le indicó al paciente controles a los 3 y 6 meses para evaluar la estabilidad del margen gingival.

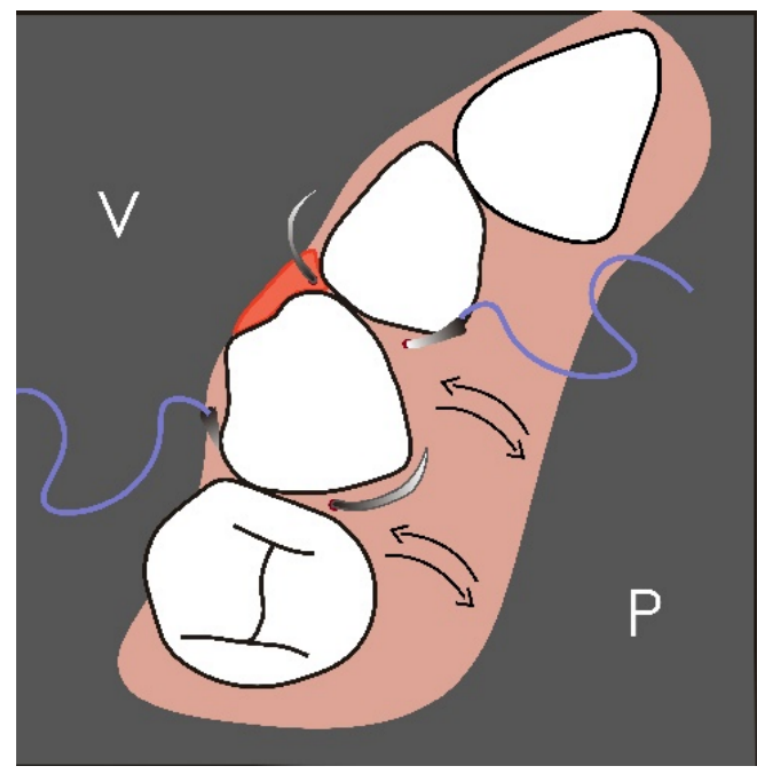

Fig. 3. Sutura del colgajo desplazado Fuente: Elaboración propia.

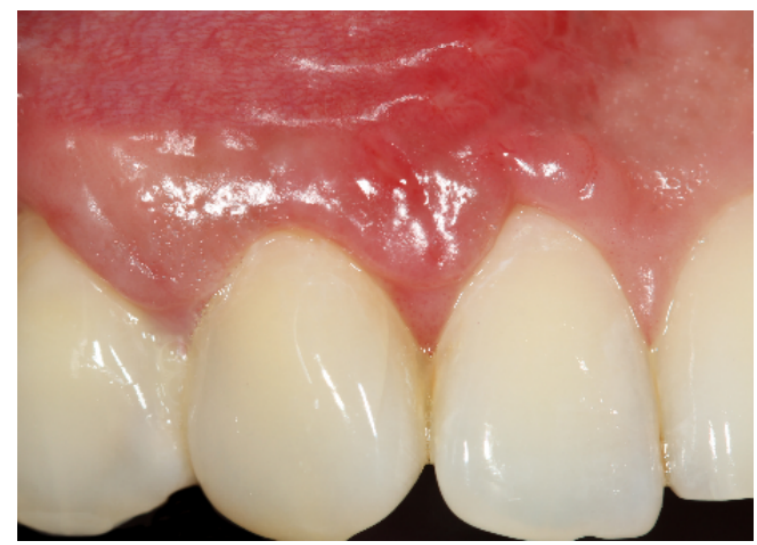

Fig. 4. Foto intraoral a los 21 días postoperatorio. Autor - Mario Calderón Barzallo.

\section{Discusión}

En este reporte de caso clínico se ha descrito la presencia de granuloma piógeno con etiología desconocida. La cual se forma con frecuencia en el tejido blando, ya sea por mala higiene oral o cambios hormonales. ${ }^{13} \mathrm{El}$ tratamiento de este tipo de lesión según varios estudios tiene gran éxito, puede realizarse por extirpación completa quirúrgica, criocirugía o cirugía láser. ${ }^{14}$

La técnica de láser puede generar menos dolor post operatorio, es un procedimiento menos invasivo, no requiere de sutura, con coagulación más rápida, pero puede generar un edema disminuido o cicatriz en el área. ${ }^{15}$ Además, el proceso para eliminación de la lesión por láser necesita de un equipo 
especializado a diferencia de la técnica quirúrgica ya que esta se realiza mediante instrumental básico. ${ }^{6}$

La técnica quirúrgica es muy favorable ya que nos permite solucionar un posible problema estético en una sola sesión clínica al momento de retirar un granuloma piógeno, con una recuperación de 7 a 14 días. $^{6}$ Sigue siendo un tratamiento de primera elección para la eliminación de lesiones gingivales, porque ayuda a abordar por completo la base y los bordes gingivales con mayor control y sutileza. ${ }^{15}$

La elección del área donante depende del sitio receptor, se debe tomar en cuenta la forma, ya que el tejido es más voluminoso en la tuberosidad del maxilar, delgado en paladar lateral y con mayor superficie en el paladar anterior. También es importante considerar el proceso fisiológico de revascularización, que puede ser denso (tuberosidad maxilar, paladar posterior) o firme (paladar anterior). ${ }^{11}$

Los beneficios del injerto de tejido conectivo subepitelial autógeno han sido aplicados cada vez más en indicaciones estéticas, como engrosamientos de tejidos blandos, tratamiento de recesión, aumento y preservación de crestas o reconstrucción de papilas. ${ }^{8}$

Se demuestra que utilizando la técnica quirúrgica convencional para eliminación de granuloma piógeno es una opción adecuada y es posible emplear injertos de tejido conectivo subepitelial de la tuberosidad del maxilar, para evitar posibles recesiones de clase I de Cairo. Obteniendo similitud en el color del área tratada, recuperación completa del tejido blando y resultados satisfactorios en cuanto a las expectativas estéticas del paciente. ${ }^{7}$

\section{Referencias Bibliográficas}

1 Rebattú y González MG, Piña Ramírez CE, Sánchez Obregón JM. Granuloma piógeno de localización atípica: reporte de un caso. Revista ADM.2017;74(4).

2 Castillo Castillo A, Doncel Pérez C. Granuloma Piógeno. Presentación de un caso. Revista Habanera de Ciencias Médicas. 2013;12(3):322-328.

3 Neville B, Damm D, Allen C.Patología oral e maxilofacial.Editora Guanabara Koogan;1998.

4 Cárdenas JLR, Vásquez ZT. Granuloma Piogeno Oral. Revista Experiencia en Medicina del Hospital Regional Lambayeque. 2018;4(1):24-27.

5 Soto A RAMV. Clasificación de enfermedades periodontales. revista Mexicana de periodontología. 2018 agosto; 9(12).

6 Gadea Rosa C, Cartagena Lay A, Cáceres La Torre A. Diagnóstico y tratamiento del granuloma piógeno oral: serie de casos. Revista odontológica mexicana. 2017:21(4):253261.

7 De Sanctis M,Zucchelli G. Coronally advanced flap: a modified surgical approach for isolated recessiontype defects: Three-year results. Journal of clinical periondontology.2007;34(3):262-268.
8 Diaz Caballero A, ARcila Aristizabal T, Arrieta González L. Injerto de tejido conectivo subpediculado y colgajo de avance coronal para el tratamiento de una recesión gingival en paciente con tratamiento de ortodoncia: Presentación de un caso. Avances en Periodoncia e Implantología Oral.2009:2(2):71-74.

9 Cairo F, Nieri M, Cincinelli S, Mervelt J, Pagliaro U. The interproximal clinical attachment level to classify gingival rescessions and predict root coverage outcomes: an explorative an reliability study. Journal of clinical periodontology.2011;38(7):661-666.

10 Zucchelli G, Clauser C, De Sanctis M, Calandriello M. Mucogingival versus guided tissue regeneration procedures in the treatment of deep recession type defects. Journal of periodontology.1998;69(2):138-145.

11 Zuhr O, Bäumer D, Hürzeler M. The addition of soft tisue replacement grafts in plastic periodontal and implant surgery: critical elements in desing and execution. Journal of clinical periodontology.2014;41:S123-S142.

12 Wachtel H, Ficki S, Zuhr O, Huerzeler MB. The DoubleSling Suture: A Modified Technique for Primary Wound Closure. European Journal of Esthetic Dentistry. 2006;1(4).

13 Jafarzadeh $H$, Snatkhani M, Mohtasham N. Oral pyogenic granuloma:a review. Journal of oral sciencie.2006;48(4):167-175.

14 Asha V, Dhanya M, Patil BA, Revanna G. An unusual presentation of pyogenic granuloma of the lower lip. Contemporary clinical dentistry. 2014;5(4):524.

15 Pick RM, Colvard MD. Current status of lasers in soft tissue dental surgery. Journal of periodontology.1993;64(7):589602 .

Recibido: 01 de octubre de 2020

Aceptado: 01 de diciembre de 2020 
